Mr. Power suggests that the brittleness of iron in cold weather may perhaps arise from somewhat similar molecular groupings occurring within the metal whilst it contracts in cooling.

One must, however, recollect that water expands when cooled from $39^{\circ} \mathrm{Fahr}$. down to the freezing-point. To this the action of cold upon iron affords no parallel, for cold renders the metal more dense. Cold brings the atoms into closer convection; hence cold will (presumably) tend to augment the strength of their mutual attraction.

July 18

H. M. ADAIR

\section{Habits of Parasitic Crah}

SOME days since $I$ obtained in the trawl a large specimen of the common Ascidian ( $A$. Viroinea) and kept it alive for about a week. It contained a specimen of the small Parasitic Crab (Pinnotheres pisum) about the size of a threepenny piece. The crab came out every night to feed about the floor of the tank, and found lodging during the day, as I afterwards proved by dissection, in the branchial cavity of the Ascidian. The crab is commonly found in the mussel, but I was not aware before that it ever wandered abroad, or sought food except within its tenement.

Kenmare

\section{W. S. G.}

\section{THE ROWTON SIDERITE}

"A" $\mathrm{N}$ addition of exceptional interest has recently been made to the collection of meteorites in the British Museum, by the presentation, on the part of the Duke of Cleveland, of a siderite (iron meteorite) which fell on his Grace's property at Rowton, near Wellington, in Shropshire, about seven miles north of the Wrekin, on the 2oth of April last. At about twenty minutes to 4 o'clock on the day mentioned, a strange rumbling noise was heard in the atmosphere, followed almost instantaneously by a startling explosion resembling a discharge of heavy artillery. There was neither lightning nor thunder, but rain was falling heavily, the sky being obscured with dark clouds for some time both before and after the incident narrated. About an hour after the explosion, Mr. George Brooks, stepson of Mr. Bayley, had occasion to go to a turf field in his occupation adjoining the Wellington and Market Drayton Railway, about a mile north of the Wrekin, when his attention was attracted to a hole cut in the ground. Probing the opening with a stick, Mr. Brooks discovered a lump of metal of irregular shape which proved to be a meteorite weighing 73 lbs. It had penetrated to a depth of eighteen inches, passing through four inches of soil and fourteen inches of solid clay down to the gravel-conclusive evidence of the force of its impact with the earth. The hole (which has been protected for further investigation) is nearly perpendicular, and the stone appears to have fallen in a south-easterly direction. Some men were at work at the time within a short distance, and they, together with many other people in the neighbourhood, heard the noise of the explosion."

The above account is taken from the Wolverhampton Chronicle, and a further notice is given in the Birmingham Daily Post of a meeting of the Natural History Society of Birmingham, at which meeting Mr. Brooks, accompanied by Mr. Gibbons, of Wolverhampton, and Mr. Wills, exhibited the meteorite. Mr. Wills described the circumstances attending the fall, stating that the "sound was heard as of something falling during a heavy shower of rain accompanied by a hissing and then a rumbling noise;" he further stated, "that when Mr. Brooks found the mass it was quite warm." Mr. Wills described it as "being black on the surface, and apparently covered with $a$ scale of metallic oxides; but at the point where it impinged on the earth the oxides had been removed, and the metallic character of the mass had been revealed."

To these interesting and accurate observations, made by the gertlemen of the locality, I have the pleasure of adding that $I$ believe it was very much owing to a resolution passed by this valuable local society, at the suggestion of the gentlemen whose names have been mentioned, to which must be added that of the well-known petrologist, Mr. Allport, of the Rev. H. W. Crosskey, and Mr. Woodward, that Mr. Ashdown, the agent of the Duke of Cleveland, took action in the matter, and obtained his Grace's assent to the meteorite being presented to the trustees of the British Museum.

On its arrival in this department it was with no small pleasure that I found the description of Mr. Wills was in all points accurate. It is, indeed, an iron meteorite, and the special interest of this statement lies in the fact that though our great collection of 3 II distinct meteorites at the museum contains 104 indubitable iron meteorites, the falls of only seven of the latter were witnessed.

The collection contains eight stony metrorites that have fallen in the British Islands; but the Rowton meteorite is only the second iron meteorite known as having been found in Great Britain.

It is thus not without a keen curiosity that one inspects a freshly fallen fragment of iron just arrived from space in our own country. One hastens to ask of it what impression the action of the atmosphere has made upon its surface during its brief transit, since most of our iron meteorites have undergone long weathering in the earth. Mr. Wills, however, has given that answer. The meteorite was covered with a very thin pellicle of the jet-black magnetic oxide of iron, and only where this had been rubbed off by abrasion with the soil is the bright metallic surface of the nickeliferous iron revealed. The little meteorite has all the usual appearance of being a fragment. Irregular and somewhat angular in form, with its edges rounded, no doubt, by the fusion and removal of no inconsiderable part of its material in its encounter with the atmosphere, it presents but very slight traces of the finger-and-thumb marks which so characteristically pit the surfaces of most stone and of some iron meteorites. Furthermore, there are fissures which penetrate deeply into the iron mass and bear testimony which there can be no gainsaying to the action of disruptive forces of tremendous strength during the hot encounter of the original mass with the atmosphere, and of which one explosion, and the rumbling echoes, possibly, of others, recorded by the witnesses bear evidence. The form of one of these fissures throws instructive light on the cause of the pitted surface of meteorites. The depth to which the little mass penetrated a stubborn soil is proof of how much momentum still remained to it, partly due, no doubt, to the approximately vertical direction in which it penetrated the atmosphere, and in some degree, too, to the higher density of an iron mass as compared with one of stone, the stony meteorites rarely penetrating to so considerable a depth. This depth of penetration and the direction of the little mass in space near north to south offer close resemblance between this iron and the iron meteorite of Nedagolla, in India.

There are indications on the metallic surface of the composite crystalline structure revealed by etching iron meteorites with acids, and known as the Widmannstattean figures, the results of the separate crystallisation of different alloys, often demarked in some of their surfaces by plates of metallic phosphides.

The development of this structure and the consequent determination of the particular type of iron meteorite to which the Rowton siderite belongs, as also the analysis of the iron itself, can only be carried out after a small portion of the meteorite shall have been carefully cut off by the aid of a lapidary's wheel, a process requiring in this particular case some careful precautions to prevent rust being hereafter formed and to reduce the loss of material to a minimum.

N. S. MASkelyne 